\title{
EFFECT OF EXTRACELLULAR MATRIX AND DENTAL PULP STEM CELLS ON BONE REGENERATION WITH 3D PRINTED PLA/HA COMPOSITE SCAFFOLDS
}

\author{
I. Gendviliene ${ }^{1, *}$, E. Simoliunas ${ }^{2}$, M. Alksne ${ }^{2}$, S. Dibart ${ }^{3}$, E. Jasiuniene ${ }^{4}$, V. Cicenas ${ }^{4}$, R. Jacobs ${ }^{5,6,7}$, \\ V. Bukelskiene ${ }^{2}$ and V. Rutkunas ${ }^{1}$
}

\author{
${ }^{1}$ Institute of Odontology, Faculty of Medicine, Vilnius University, Vilnius 08217, Lithuania \\ ${ }^{2}$ Department of Biological Models, Institute of Biochemistry, Life Sciences Centre, Vilnius University, \\ Vilnius 10257, Lithuania \\ ${ }^{3}$ Department of Periodontology, Henry M. Goldman School of Dental Medicine, Boston University, \\ Boston, MA 02118, USA \\ ${ }^{4}$ Prof. K. Barsauskas Ultrasound Research Institute, Kaunas University of Technology, Kaunas 51423, \\ Lithuania \\ ${ }^{5}$ Omfs Impath Research Group, Department of Imaging and Pathology, Faculty of Medicine, University of \\ Leuven, 3000 Leuven, Belgium \\ ${ }^{6}$ Department of Oral and Maxillofacial Surgery, University Hospitals Leuven, 3000 Leuven, Belgium \\ ${ }^{7}$ Department Dental Medicine, Karolinska Institute, 17177 Stockholm, Sweden
}

\begin{abstract}
The demand for bone grafting procedures in various fields of medicine is increasing. Existing substitutes in clinical practice do not meet all the criteria required for an ideal bone scaffold, so new materials are being sought. This study evaluated bone regeneration using a critical-size Wistar rat's calvarial defect model. 12 male and 12 female rats were evenly divided into 3 groups: 1 . Negative and positive (Geistlich Bio-Oss ${ }^{\circledR}$ ) controls; 2. polylactic acid (PLA) and PLA/hydroxyapatite (HA); 3. PLA/HA cellularised with dental pulp stem cells (DPSC) and PLA/HA extracellular matrix (ECM) scaffolds. PLA/HA filament was created using hot-melt extrusion equipment. All scaffolds were fabricated using a 3D printer. DPSC were isolated from the incisors of adult Wistar rats. The defects were evaluated by micro-computed tomography $(\mu \mathrm{CT})$ and histology, 8 weeks after surgery. $\mu \mathrm{CT}$ revealed that the Bio-Oss group generated $1.49 \mathrm{~mm}^{3}$ and PLA/HA ECM $1.495 \mathrm{~mm}^{3}$ more bone volume than the negative control. Histology showed a statistically significant difference between negative control and both (Bio-Oss and PLA/HA ECM) groups in rats of both genders. Moreover, histology showed gender-specific differences in all experimental groups and a statistically significant difference between cellularised PLA/HA and PLA/HA ECM groups in female rats. Qualitative histology showed the pronounced inflammation reaction during biodegradation in the PLA group. In conclusion, the bone-forming ability was comparable between the Bio-Oss and PLA/HA ECM scaffolds. Further research is needed to analyse the effects of ECM and PLA/HA ratio on osteoregeneration.
\end{abstract}

Keywords: Biocomposite scaffolds, extracellular matrix, PLA/HA scaffolds, bone regeneration, dental pulp stem cells, Geistlich Bio-Oss, micro-computer tomography, histology.

*Address for correspondence: Ieva Gendviliene, Vilnius University, Zalgirio g. 117, LT- 08217, Vilnius, Lithuania.

Telephone number: +370 52727589 Fax number: +370 52398705 Email: ieva.gendviliene@gmail.com

Copyright policy: This article is distributed in accordance with Creative Commons Attribution Licence (http://creativecommons.org/licenses/by-sa/4.0/).

\begin{tabular}{|c|c|c|c|}
\hline & List of abbreviations & DPSC & dental pulp stem cells \\
\hline & & ECM & extracellular matrix \\
\hline $2 \mathrm{D}$ & 2 dimensional & EDTA & ethylenediaminetetraacetic acid \\
\hline $3 \mathrm{D}$ & 3 dimensional & FDA & United States Food and Drug \\
\hline Bio Oss & Geistlich Bio-Oss ${ }^{\circledR}$ & & Administration \\
\hline BSA & bovine serum albumin & GM & growth medium \\
\hline DAPI & 4',6-diamidino-2-phenylindole & GV & grey values \\
\hline & dihydrochloride & HA & hydroxyapatite \\
\hline DPBS & Dulbecco's phosphate-buffered saline & IL-1 & interleukin-1 \\
\hline
\end{tabular}




$\begin{array}{ll}\text { IMDM } & \begin{array}{l}\text { Iscove's modified Dulbecco's medium } \\ \text { phosphate-buffered saline }\end{array} \\ \text { PBS } & \text { polylactic acid } \\ \text { PLA } & \text { Arg-Gly-Asp } \\ \text { RGD } & \text { streptavidin phycoerythrin } \\ \text { RPE } & \text { sodium dodecyl sulphate } \\ \text { SDS } & \text { sodium citrate buffer } \\ \text { SSC } & \text { stereolithography } \\ \text { STL } & \text { tumour necrosis factor- } \alpha \\ \text { TNF- } \alpha & \text { micro-computed tomography }\end{array}$

\section{Introduction}

Currently, there is an increasing number of clinical situations in which large bone defects must be treated. More than 2 million bone grafts are carried out each year in the USA alone, including alveolar boneaugmentation procedures (Campana et al., 2014). Surveys show that the percentage of edentulous persons over 65 years old differ among the countries from 20 to $60 \%$ (Hopcraft et al., 2012; Saintrain and de Souza, 2012; Sveikata et al., 2012). One of the most effective ways of treating tooth loss is by using dental implants. However, considering bone deficiencies, almost every second dental implant surgery needs bone augmentation (Cha et al., 2016).

The bone augmentation is performed by restoring the bone defect with an autologous bone graft or various substitutes (Anagnostopoulos et al., 2018). New bone formation will begin if the harvested bone graft or substitute is revascularised (Valenti et al., 2016). Although autologous bone grafts have been considered as the "gold standard" (Liang et al., 2017), several drawbacks must be taken into consideration, including a limited number of donor sites and volume (Liang et al., 2017) or postoperative complications at a donor site (pain, haematoma, sensory loss) (Bhatt and Rozental, 2012).

Existing bone substitutes (allogenic, xenogenic or alloplastic) are characterised by osteoconductive but not osteoinductive features, as such that these cannot stimulate osteogenesis themselves (Leventis et al., 2018). One of the most established xenogenic bone substitutes for regenerative dentistry is Bio-Oss, which leads to high implant survival rates over a long-term follow-up time of 12 to 14 years (Jung et al., 2013). However, an ideal bone substitute should be a biocompatible substance, not causing inflammatory reactions in the surrounding tissues, with bactericidal, osteoconductive, osteoinductive, and biodegradable properties, meanwhile being sterile, easily adaptable to the existing defect and cheap (Jordana et al., 2017). One of the most advanced alternatives to the bone substitutes mentioned above is a $3 \mathrm{D}$ composite scaffold that can stimulate cellular responses and is essential for regulating cell adhesion, proliferation, migration and differentiation (Narayanan et al., 2018).

PLA is one of the organic materials that could be used for the creation of 3D composite scaffolds. PLA is a biocompatible and biodegradable substance, which is approved by the FDA for clinical applications, and it can be easily shaped by a 3D printer (Costantino et al., 2001; Li et al., 2015; Tyler et al., 2016). On the other hand, PLA by itself is not structurally strong enough to withstand the requirements of weightbearing bone fracture fixation devices (Sheikh et al., 2015). Nonetheless, HA has excellent osteoconductive properties. It amounts to about $70 \%$ of the dry mass of bones, which makes it a perfect component for bone regeneration procedures (Fricain et al., 2013; Han et al., 2018). Furthermore, introducing HA to the PLA would create a new composite material, which can demonstrate needed properties such as stimulation of stem cells to differentiate into osteoblasts, a better stem cell attachment, proliferation, and migration (Frohbergh et al., 2012; Pati et al., 2015). Additionally, HA can suppress heterogeneous degradation, which is related to the acidic degradation products from PLA as these reduce the $\mathrm{pH}$ of the local environment and may increase bone resorption (Frohbergh et al., 2012).

Moreover, composite 3D scaffolds may be modified with various stem cells for better osteoinductivity (Pati et al., 2015). It is expected that the cells seeded on the scaffolds before implantation will release growth factors that will increase migration of the stem cells to the site of the injury, induce angiogenesis, and osteogenic differentiation (Neto and Ferreira, 2018; Wu et al., 2019). DPSCs are one of the best candidates in translational medicine and bone tissue regeneration due to their high degree of proliferation and efficacy in the production of fine bone particles (Alom et al., 2017; Ballini et al., 2018; Langhans et al., 2016). These cells produce the ECM proteins, which become ossified when cells turn into osteoblasts. Existing studies show that bone and bone marrow stem cells are also suitable for ECM production, but these cells do not produce calcified bone particles upon differentiation into osteoblasts (Nakajima et al., 2018).

Another technique of bone tissue engineering is decellularisation, which allows the retention of the native ECM molecules on the remaining scaffold and reduces the onset of inflammation by decreasing the expression of TNF- $\alpha$ and IL-1 (Wu et al., 2019). The ECM is a microenvironment composed of structural and functional macromolecules that provide cellular support and biochemical signals to regulate the biological and physical cues that dictate mesenchymal stem cell function and overall fate (Nakajima et al., 2018; Graziano et al., 2008). The organisation of each ECM is unique and depends on the tissue structure. The main components of ECM are collagen I, collagen III, fibronectin, laminin, and various types of glycosaminoglycans and proteoglycans (Antebi et al., 2015). The ECM produced by bone-differentiating cells consists of various glycoproteins and proteoglycans that have specific RGD amino acid sequences in their polypeptide chains, which are recognised and bound to receptors on the cell surface. Thus, the presence of ECM results in better cell adhesion, proliferation, 
differentiation, and osteogenesis (Addi et al., 2017; Bonnans et al., 2014).

Bone substitute materials currently used in clinical practice are osteoconductive and have many limitations, so new materials and applications are being developed. The purpose of this study was to evaluate the new bone formation in vivo effect of 3D-printed PLA/HA scaffolds, enhanced with DPSC or the ECM they produce. It was hypothesised that cellularised PLA/HA and PLA/HA ECM scaffolds should give new bone formation, comparable to the Bio-Oss, due to their osteoinductive features.

\section{Materials and Methods}

\section{Animals}

24 four-month old Wistar rats (approximate weight $300 \mathrm{~g}$ ) were used. Approval of the Ethics Committee and permission for the experimentation was received from the State Food and Veterinary Service of Lithuania, No G2-40, 2016-03-18. Inbred Wistar rats were obtained from the Department of Biological Models at Vilnius University, Life Sciences Centre, Institute of Biochemistry, Vilnius, Lithuania. Animal experiments were carried out in the same premises. The sample size was counted using $\mathrm{G}^{*}$ power software v. 3.1.9.7 (https://download.cnet. com/GPower/3000-2054_4-10647044.html) (one-way ANOVA test with a priori analysis: $\alpha=0.05$, power $=0.8$, effect size $f=0.75$ ). The animals were divided evenly into 3 groups: 1 . Negative and positive (BioOss) controls; 2. PLA and PLA/HA scaffolds; 3. PLA/HA cellularised with DPSC and PLA/HA ECM scaffolds. There were 4 female and 4 male animals in each group. During the whole experimental period, the rats were kept in a monitored environment $\left(21^{\circ} \mathrm{C}\right.$; $12: 12 \mathrm{~h}$ light cycle) and received a standardised diet and water ad libitum.

\section{Materials}

PLA particles (molecular weight $42.7 \mathrm{~kg} / \mathrm{mol}$, 100$800 \mu \mathrm{m}$ diameter; STP Chem Solutions, Nonthaburi, Thailand) and $50 \mu \mathrm{m}$ size HA particles (Riga Technical University, Riga, Latvia) were used for composite filament creation. Bio-Oss ${ }^{\circledR}$ (Geistlisch Pharmaceutical, Wolhusen, Switzerland) granules, $0.25-1 \mathrm{~mm}$ diameter, were used as for positive controls. Materials used for cell culture: IMDM (Gibco); penicillin and streptomycin (Gibco); PBS (Gibco); EDTA (Sigma-Aldrich); trypsin (Gibco); dexamethasone (Sigma-Aldrich); $\beta$-glycerophosphate (Sigma-Aldrich); L-ascorbic acid-2-phosphate (Sigma-Aldrich); ethanol 96 \% (Vilniaus Degtine); Ammonium hydroxide solution $\sim 10 \%$ in $\mathrm{H}_{2} \mathrm{O}$ (Sigma-Aldrich); type I collagenase (Sigma-Aldrich); hyaluronidase (Sigma-Aldrich); BSA (AppliChem $\mathrm{GmbH}) ; \mathrm{DPBS}, 10 \times($ Gibco); goat anti-mouse IgG coated magnetic beads (New England Biolabs); primary mouse antibodies to CD45, CD54, CD14, CD90 (Merck Millipore), CD44 (Cell Signaling
Technology), CD13 (Santa Cruz Biotechnology), CD31 (Abcam); sirius red dye $[1 \mathrm{mg} / \mathrm{mL}$, direct red 80 (Sigma-Aldrich), diluted in $1.3 \%$ picric acid (Sigma-Aldrich)]; DAPI (TRIzol, Life Technologies); L- ascorbic acid 2-phosphate (Sigma-Aldrich); trisodium citrate dihydrate (Sigma-Aldrich); SDS (Sigma-Aldrich); $20 \times$ SSC [3mol/L NaCl (SigmaAldrich) and $0.3 \mathrm{~mol} / \mathrm{L}$ trisodium citrate solution (Sigma-Aldrich), prepared in deionised water, $\mathrm{pH}$ 7.0. Required $\mathrm{pH}$ was adjusted with $10 \mathrm{~mol} / \mathrm{L} \mathrm{NaOH}$ (Sigma-Aldrich)]; goat anti-mouse IgG secondary antibody, RPE conjugated (Invitrogen); mouse IgG2a isotype control (Abcam). All materials were used as received.

\section{Composite filament preparation and fabrication of the scaffolds}

The composite filament for printing was produced using a Filabot Original (Filabot HQ, Barre, VT, USA) filament extruder system, mixing PLA and HA powders at the ratio of $9: 1(\mathrm{w} / \mathrm{w})$. All scaffolds were fabricated using the FFF 3D printer (Pharaoh XD 20, Mass Portal, Latvia). Other details can be found in a previously published article (Gendviliene et al., 2020). The average pore size was $450 \mu \mathrm{m}$, with total porosity of $58 \%$ according to the STL production file. The width and height of the threads were 0.4 and $0.2 \mathrm{~mm}$ respectively, and there were 8 layers of threads (Fig. $1 \mathbf{a}, \mathbf{b})$. The geometry of the scaffolds was composed of 3D micro-structured weaves with threads rotated at an angle of $60^{\circ}$ with respect to the pair of the previous layer to create a hexagonal inner geometry (Fig. 1c). The morphology of the PLA and PLA/HA scaffolds was evaluated using a Hitachi TM-1000 tabletop scanning electron microscope and the results of the printing accuracy were published previously (Gendviliene et al., 2020). Dimensions of the scaffolds were $30 \times 30 \times 1.6 \mathrm{~mm}$. Necessary $5.5 \mathrm{~mm}$ circles were formed with laser-light filament fabrication. Sterilisation of PLA and PLA/HA scaffolds was done with ethylene oxide gas. The aeration lasted for $4 \mathrm{~d}$.

\section{Stem cell isolation}

DPSCs were isolated from the incisor dental pulp of 3 months old Wistar rats ( $n=4$ pulp samples in each extraction). Cell isolation and characterisation were performed, as previously described (Alksne et al., 2019). Briefly, dental pulp samples were washed several times with IMDM supplemented with $100 \mu \mathrm{g} / \mathrm{mL}$ Primocin ${ }^{\mathrm{TM}}$ and mechanically minced into $<1 \mathrm{~mm}^{3}$ fragments that were transferred to the digestive solution ( $0.5 \%$ collagenase type $1,0.3 \%$ hyaluronidase, $0.25 \%$ trypsin and $0.02 \%$ EDTA) and were shaken for $30-45 \mathrm{~min}$ at $37^{\circ} \mathrm{C}$. Later on, IMDM supplemented with $10 \%$ PBS and antibiotic (100 U/ $\mathrm{mL}$ penicillin, $100 \mathrm{mg} / \mathrm{mL}$ streptomycin), referred to as GM, was added and centrifuged twice at $300 \times g$ for $10 \mathrm{~min}$ (CL10 centrifuge Thermo Scientific). The supernatant was removed, and the cells were seeded in GM. When cells reached 70-80 \% confluence, CD44positive cells were extracted using magnetic beads 
a
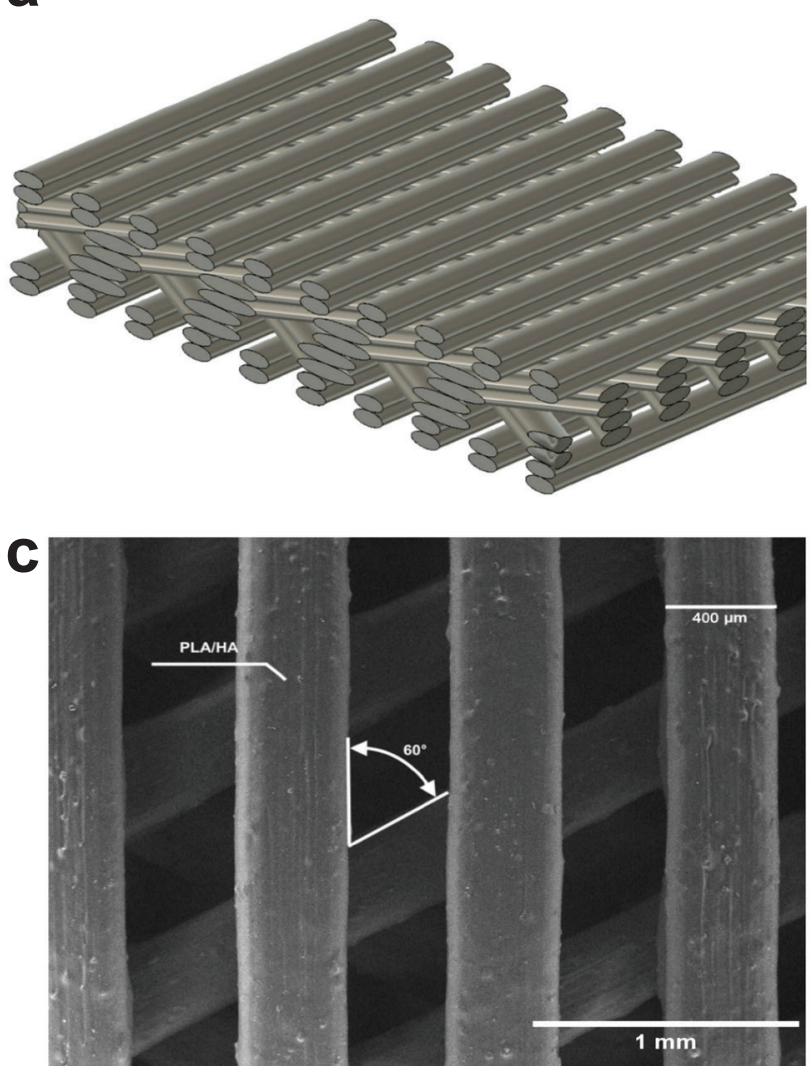

b
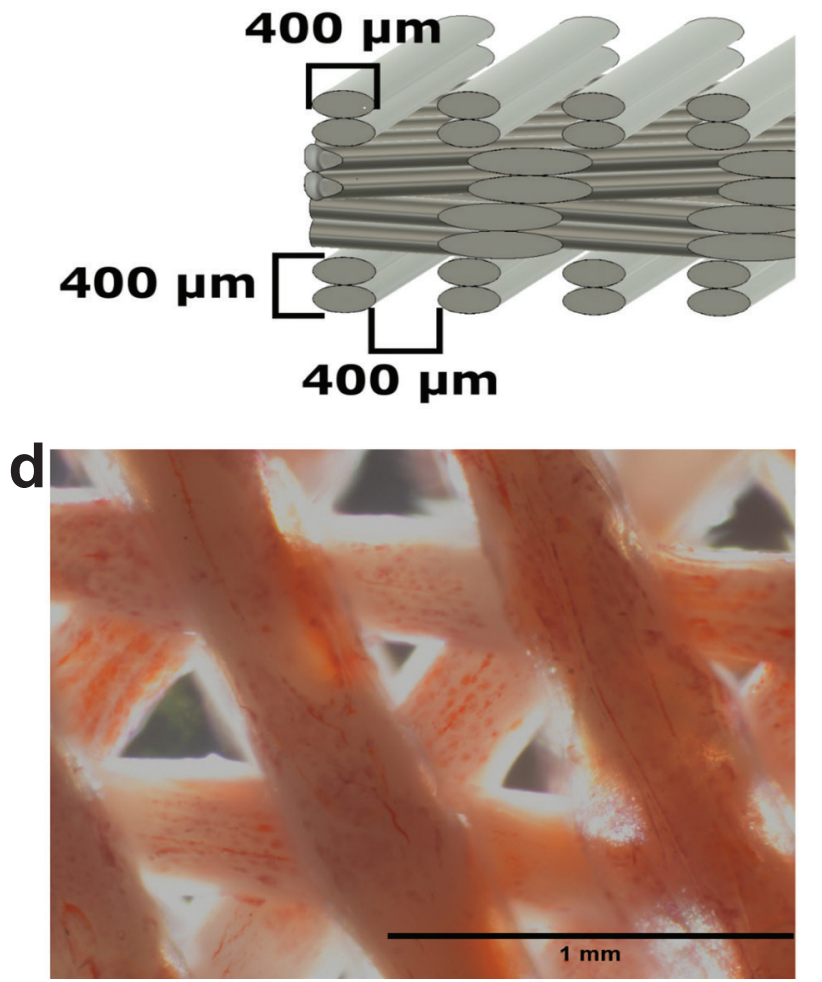

Fig. 1. The morphology of the scaffolds. (a) The scaffold from side according to the STL file; (b) the diameter of the threads from the STL file; (c) the top view of PLA/HA scaffold obtained by scanning electron microscopy, threads are rotated at a $60^{\circ}$ angle; (d) osteogenically differentiated DPSC grown on PLA/HA scaffold for $21 \mathrm{~d}$. Red colour depicts calcium deposits in cells formed ECM (stained with alizarin red S).

coated with antibodies against the CD44 antigen. This separation procedure was performed according to BioLab's magnetic beads recommendations using the KingFisher ${ }^{\mathrm{TM}} \mathrm{mL}$ (Thermo Scientific) purification system. Cells used in the experiments were up to 12 passages. Cells were cultivated in IMDM supplemented with $10 \%$ PBS and antibiotics (100 U/mL penicillin, $100 \mathrm{mg} / \mathrm{mL}$ streptomycin) at $37^{\circ} \mathrm{C}, 5 \% \mathrm{CO}_{2}$ environment.

\section{Production of cellularised and decellularised scaffolds}

For the production of cellularised and decellularised scaffolds, DPSCs were seeded on PLA/HA scaffolds at a density of 4,000 cells $/ \mathrm{cm}^{2}$ and grown in osteogenesisinducing medium, which was composed of GM enriched with $50 \mathrm{nmol} / \mathrm{L}$ dexamethasone, $25 \mu \mathrm{g} / \mathrm{mL}$ ascorbic acid and $10 \mathrm{mmol} / \mathrm{L} \beta$-glycerophosphate. The medium was changed every second/third day for $21 \mathrm{~d}$ (Fig. 1d). After this differentiation period, cellularised scaffolds were directly used for Wistar rats' bone defect regeneration. Decellularised scaffolds were produced from cellularised ones. Cells grown on scaffolds were washed twice with PBS and then frozen at $-80{ }^{\circ} \mathrm{C}$. Scaffolds were then allowed to defrost and were washed with deionised water, then frozen again. In summary, 5 freeze-thaw cycles with deionised water washing were performed. Then, scaffolds were incubated in $25 \mathrm{mmol} / \mathrm{L} \mathrm{NH}_{4} \mathrm{OH}$ for $20 \mathrm{~min}$ to wash out any remaining DNA. Finally, scaffolds were washed 6 times with deionised water, and then they were ready for use in surgery.

\section{Collagen amount on scaffolds}

The amount of collagen on scaffolds was determined using a sirius red assay. Sirius red dye was added to each sample and incubated for $1 \mathrm{~h}$ at room temperature with $25 \mathrm{rpm}$ shaking. The sirius red solution was then removed; the samples were washed with $0.01 \mathrm{~mol} / \mathrm{L} \mathrm{HCl}$ in PBS and centrifuged at $100 \times g$ for $30 \mathrm{~s}$ (centrifuge HERMLE Labortechnik $\mathrm{GmbH}$ ). On the scaffolds, sirius red residues were dissolved in $0.1 \mathrm{~mol} / \mathrm{L} \mathrm{NaOH}$ in PBS by incubating for $30 \mathrm{~min}$ at room temperature with $25 \mathrm{rpm}$ shaking. The absorbance was measured using a microplate spectrophotometer Varioskan Flash (Thermo Scientific) at $550 \mathrm{~nm}$.

\section{DNA amount on scaffolds}

DAPI assay measured the DNA residues on the decellularised scaffolds. Briefly, samples were lysed with $0.04 \%$ SDS solution prepared in the SSC buffer by shaking $(300 \mathrm{rpm})$ for $30 \mathrm{~min}$ at $37^{\circ} \mathrm{C}$. Obtained lysates were diluted $2 \times$ with SSC and mixed $(1: 1)$ with $4 \mu \mathrm{g} / \mathrm{mL}$ DAPI solution in $1 \times$ SSC; after $1 \mathrm{~h}$ of incubation in the dark by shaking (300 rpm), the DAPI- 
DNA fluorescence was measured $\left(\lambda_{\text {excitation }}=360 \mathrm{~nm}\right.$, $\lambda_{\text {emission }}=460 \mathrm{~nm}$ ) using a microplate reader Varioskan Flash (Thermo Scientific).

\section{Surgical procedures}

Animals were anaesthetised with an intraperitoneal injection of $2.4 \mathrm{~mL} / \mathrm{kg}$ ketamine hydrochloride (100 mg/mL; Rotex Medica GMBH, Tritau, Germany) and $5 \mathrm{mg} / \mathrm{kg}$ xylazine (2\%; Alfasan, Woerden, the Netherlands). The dorsal part of the cranium was shaved and aseptically prepared with octenidine dihydrochloride (Octenisept, Schülke \& Mayr GmbH, Germany). Local anaesthesia was done by injecting $0.25 \mathrm{~mL}$ of $2 \%$ lidocaine $(20 \mathrm{mg} / \mathrm{mL}$; Baxter Holding B.V., Utrecht, the Netherlands) subcutaneously along the sagittal midline of the skull. One vertical incision was made in the middle of the posterior part of the cranium and a full-thickness flap was reflected to expose the parietal and frontal bones (Fig. 2a). A $5.5 \mathrm{~mm}$ circular critical size defect (2 per animal) with at least a $1.5 \mathrm{~mm}$ bone bridge between them were made with a calibrated trephine burr (Hager \& Meisinger $\mathrm{GmbH}$, Germany) mounted on a contraangle and irrigated with saline solution (Fig. 2b). Scaffolds were randomly implanted as inlay-onlay grafts at the defect sites in all three groups (Fig. $2 \mathbf{c}, \mathbf{e})$. After implantation, the flap was closed and the periosteum and skin were sutured with resorbable sutures (Vicryl 5/0, Ethicon ${ }^{\circledR}$, Johnson\&Johnson, Amersfoort, the Netherlands) (Fig. 2d). Following surgery, the rats were transferred to the cages and housed singly for 8 weeks. The first dose of Buprenorphine $\mathrm{HCl} 0.01 \mathrm{mg} / \mathrm{kg}$ (0.3 mg/mL; Richter Pharma AG, Wels, Austria) was given $3 \mathrm{~h}$ after the surgery subcutaneously and then 2 times per day, $3 \mathrm{~d}$ for postoperative analgesia. Specimens were harvested after 8 weeks and were immediately fixed in $10 \%(\mathrm{v} / \mathrm{v})$ neutral buffered formalin. The defects were evaluated by $\mu \mathrm{CT}$ and histological analysis.

\section{$\mu C T$ analysis}

An X-ray 3D computer tomography device RayScan 250 E (RayScan Technologies GmbH, Germany) with $10-230 \mathrm{kV}$ microfocus X-ray source was used for the evaluation of bone defect regeneration. To collect 3D data of investigated objects, the X-ray source irradiates the test object with the conical beam, and a 2D image at the flat panel detector with 2,048 $\times 2,048$ pixels is recorded. During each measurement, the object was rotated, and 1,800 projections were acquired at a $100 \mathrm{kV}$ voltage and $200 \mu \mathrm{A}$ current with a $666 \mathrm{~ms}$ integration time. A voxel size of $20 \mu \mathrm{m}$ was achieved. The dimensional analysis was carried out with Avizo for Industrial Inspection 9.70 (FEI-SAS, Thermo Fischer Scientific Inc.) software. A special algorithm was developed for the regenerated bone volume calculation from the $\mu \mathrm{CT}$ data. Regenerated skull bone calculation algorithm includes finding the perpendicular vector to the trepanation zone plane. Then, parallel to this vector, a $5.5 \mathrm{~mm}$-diameter zone was cut using a cylindrical template. Only material from inside this cylinder was used for analysis. It included soft tissues, new bone, and artificial implants used to improve the bone regeneration process. These 3 material groups differed in density and were separated using this parameter. Soft tissue and PLA GV ranged up to 20,000, new bone values were from 20,000 to 44,000, and HA values were above 44,000. A 16 bit detector was used for $\mu \mathrm{CT}$, so the full GV scale range was from 1 to 65536. Knowing these values allowed the calculation of voxel count. Voxels were attributed to 1 of the 3 groups, according
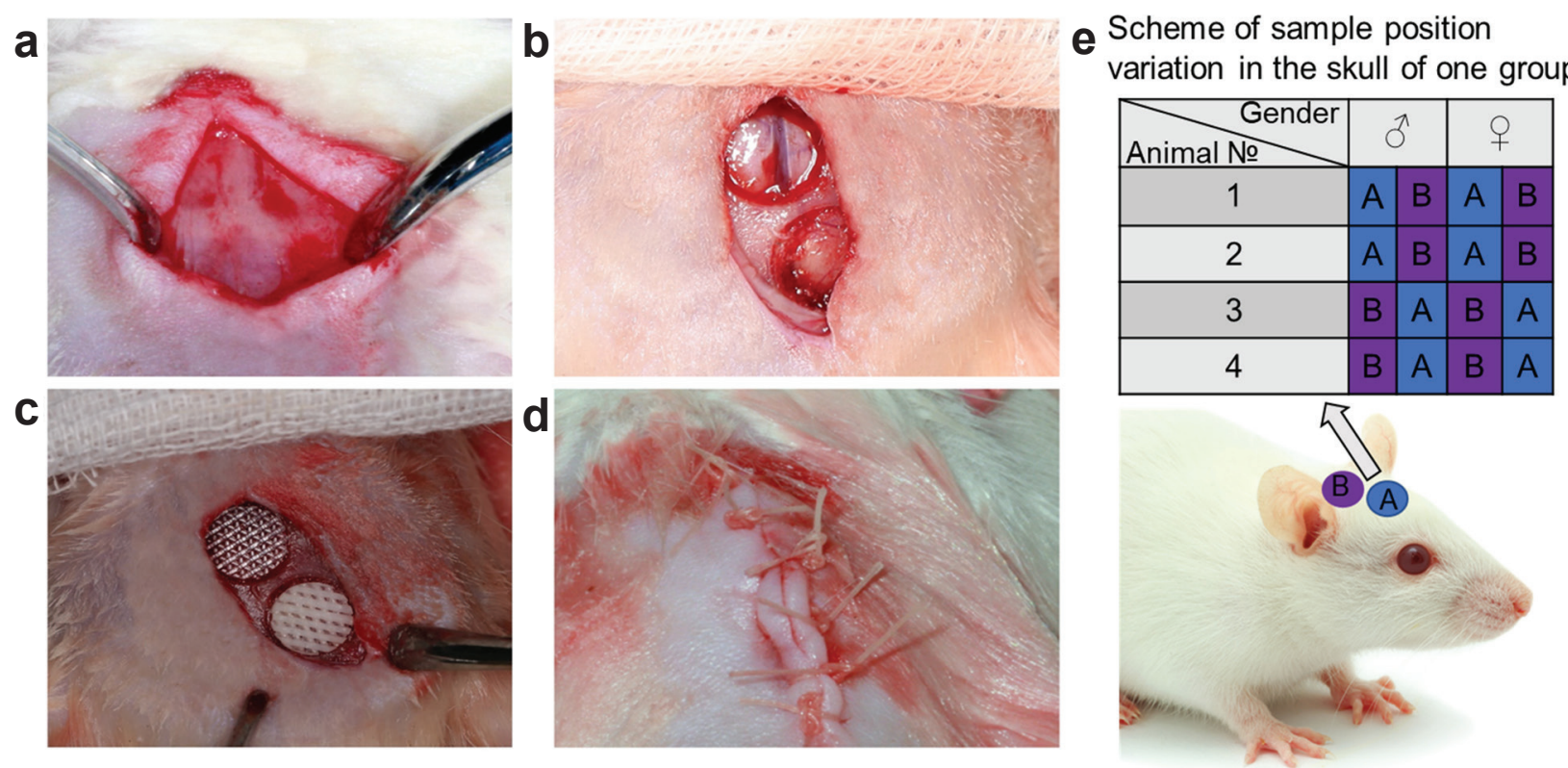

Scheme of sample position variation in the skull of one group

Fig. 2. Surgical procedure. (a) Surgical site; (b) $2 \times 5.5 \mathrm{~mm}$ circular defects; (c) implanted PLA and PLA/HA scaffolds; (d) sutured wound; (e) scheme of sample position variation in the skull of 1 group. A and B mean the identification of the samples in the group. Group 1: $\mathrm{A}=$ negative control, $\mathrm{B}=\mathrm{Bio}-\mathrm{Oss}$. Group 2: $\mathrm{A}=\mathrm{PLA}$, $\mathrm{B}=\mathrm{PLA} / \mathrm{HA}$. Group 3: A = PLA/HA cellularised with dental pulp stem cells, B = PLA/HA ECM scaffolds. 
to their GV. Later, each group's voxel count sum was multiplied by the voxel volume, which produced the cut region's overall material volume. Based on the $\mu \mathrm{CT}$ results, bone volume $\left(\mathrm{mm}^{3}\right)$ of the regenerated bone was calculated.

\section{Histology}

After $\mu \mathrm{CT}$ analysis, bone specimens were decalcified in a $10 \%$ EDTA with $10 \%$ formalin solution, pH 7.07.4 (Laboratory of National Centre of Pathology, Vilnius, Lithuania) for 2 weeks. Slices were obtained from the central part, $1.3 \mathrm{~mm}$ and $2.6 \mathrm{~mm}$ away from the centre of each healed bone defect, embedded in paraffin wax, sectioned longitudinally into 5 histological sections ( $3 \mu \mathrm{m}$ thick) and stained with haematoxylin and eosin. The stained preparations were examined using a light microscope (Olympus BX41TF, Olympus Optical Co. Ltd., Japan) and the entire section was evaluated for qualitative analysis. Images were obtained of each section with ScanScope XT (Aperio, USA). The area of new bone in the defect site was determined as the bony area $\left(\mathrm{mm}^{2}\right)$ using the software Aperio ImageScope (Leica Biosystems Imaging, USA).

\section{Statistical analysis}

All statistical analyses were performed using the $\mathrm{R}$ Project software (RStudio v1.1.442). Data are presented as mean \pm standard deviation. Statistically significant differences between the gender groups were determined using a $t$-test. One-way analysis of variance (ANOVA) was performed between the sample groups, and the Tukey post-hoc test was used. Differences were considered statistically significant when $p<0.05$.

\section{Results}

\section{Overall}

Tested scaffolds were divided into 4 groups: PLA, PLA/HA, PLA/HA cellularised with DPSCs, and PLA/HA ECM. PLA/HA scaffolds cellularised with DPSCs and PLA/HA ECM scaffolds were prepared according to a previous in vitro study (Alksne et al., 2020). The amount of the DNA residues present was not significant and showed almost the same results as the control PLA/HA group (Fig. $3 \mathbf{b}$ ). The collagen amount was statistically significantly lower in the PLA/HA ECM group than in the cellularised PLA/HA group $(p<0.001)$ but higher than PLA/HA group $(p<0.05)$ (Fig. 3a). All animals survived for the duration of the study without complications. At 8 weeks, there were no clinical signs of infection, haematoma, or necrosis at the defect sites. The scaffolds were stable and did not move from the created defects.

\section{$\mu C T$ evaluation}

The acquired $\mu \mathrm{CT}$ data was processed using a developed algorithm to determine the volume of bone formation in the regions of interest. The processed radiological imaging results obtained from the $\mu \mathrm{CT}$ after 8 weeks of healing are shown in Fig. 4 .

$\mu \mathrm{CT}$ evaluation showed no significant genderspecific differences in new bone formation of negative control and Bio-Oss groups $(p>0.05)$ (Fig. 5). A statistically significant gender-specific difference was detected in PLA and cellularised PLA/HA groups (Fig. 5). The Bio-Oss group generated $1.49 \mathrm{~mm}^{3}$ and PLA/HA ECM $1.495 \mathrm{~mm}^{3}$ more bone volume than the negative control (Table 1).
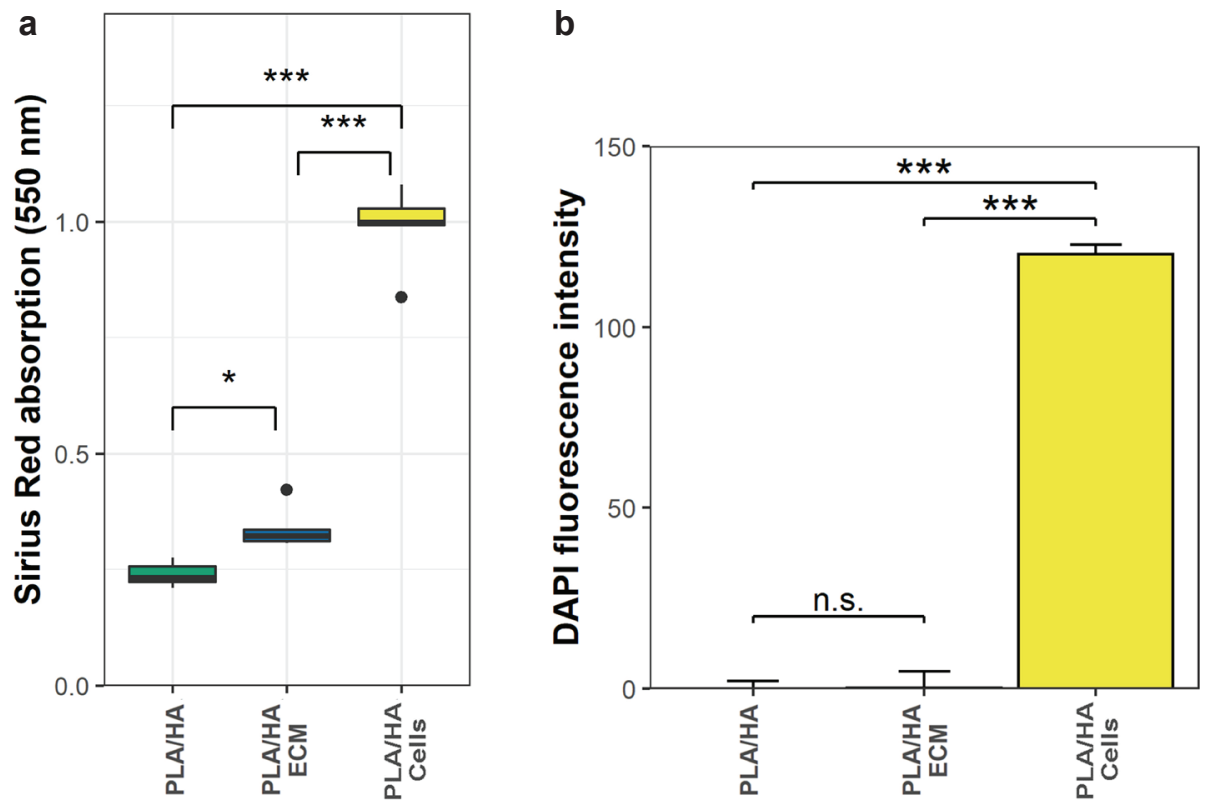

Fig. 3. The effectiveness of PLA/HA DPSC scaffold decellularisation. (a) Box plot representing collagen amounts on the scaffolds, as evaluated by Sirius Red staining. (b) Quantitative evaluation of DNA left on the scaffolds, using DAPI dye before and after decellularisation procedure. Results are presented as mean \pm SD. * and $^{* * *}$ mark the statistically significant differences between the groups at $p<0.05$ and $p<0.001$, respectively. 
Table 1. $\mu \mathrm{CT}$ and histology results according to gender. All parameters are presented as mean \pm SD.

\begin{tabular}{|c|c|c|c|c|c|c|c|}
\hline \multicolumn{2}{|c|}{ Results } & $\begin{array}{c}\text { Negative } \\
\text { control }\end{array}$ & Bio-Oss & PLA & PLA/HA & PLA/HA cells & PLA/HAECM \\
\hline \multirow{2}{*}{$\begin{array}{l}\mathrm{BV}\left(\mathrm{mm}^{3}\right) \\
\mu \mathrm{CT}\end{array}$} & female & $2.31 \pm 0.73$ & $3.85 \pm 0.10$ & $1.50 \pm 0.33$ & $2.29 \pm 0.27$ & $2.47 \pm 0.36$ & $3.01 \pm 0.26$ \\
\hline & male & $2.80 \pm 0.39$ & $4.24 \pm 0.51$ & $3.76 \pm 0.43$ & $3.86 \pm 0.99$ & $4.11 \pm 0.72$ & $5.09 \pm 1.27$ \\
\hline \multirow{2}{*}{$\begin{array}{l}\text { New bone }\left(\mathrm{mm}^{2}\right) \\
\text { Histology }\end{array}$} & female & $2.04 \pm 0.34$ & $3.35 \pm 0.26$ & $1.90 \pm 0.07$ & $2.32 \pm 0.09$ & $2.81 \pm 0.30$ & $3.10 \pm 0.27$ \\
\hline & male & $2.34 \pm 0.96$ & $4.15 \pm 0.58$ & $2.52 \pm 0.33$ & $2.90 \pm 0.06$ & $3.66 \pm 0.29$ & $3.80 \pm 0.24$ \\
\hline
\end{tabular}

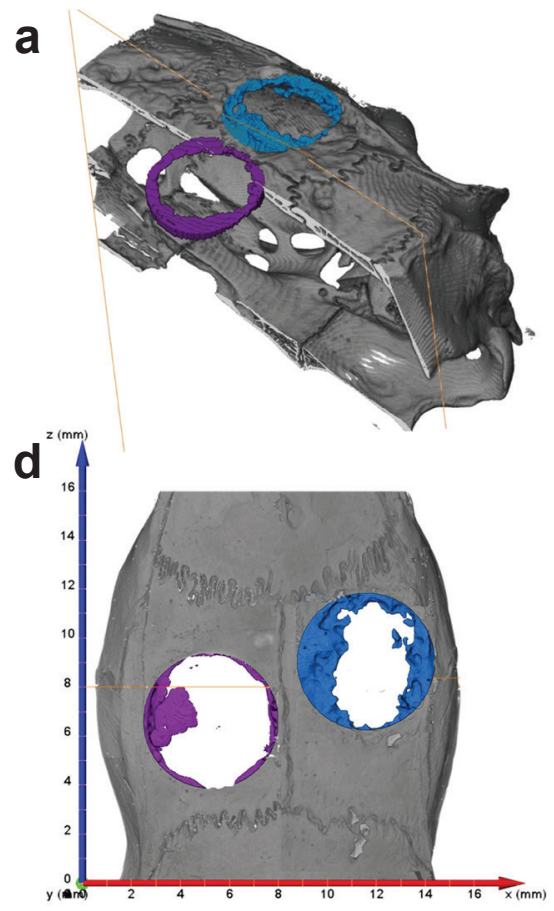

b

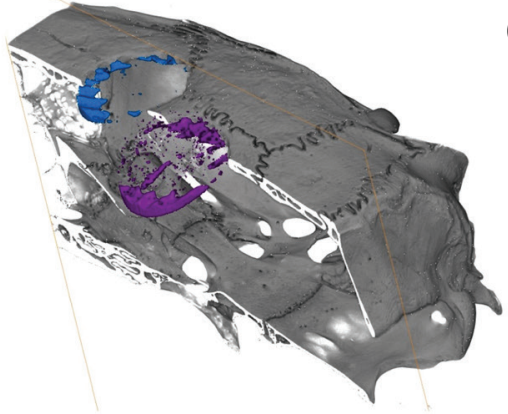

e

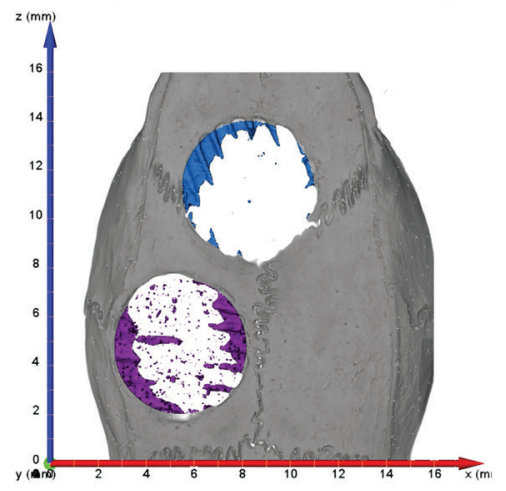

C

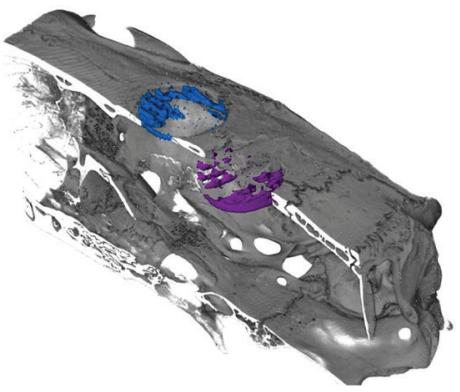

$\mathbf{f}$

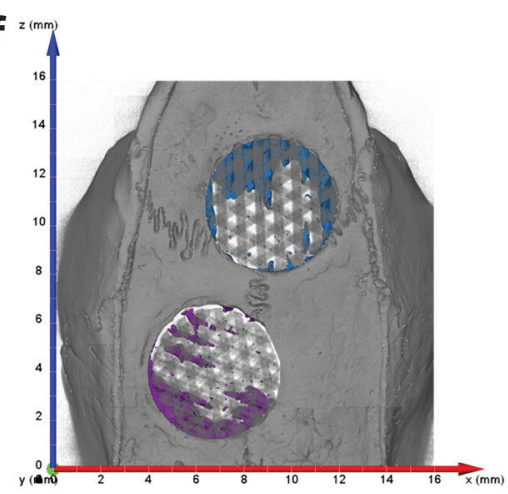

Fig. 4. Processed $\mu \mathrm{CT}$ images taken with an X-ray 3D Computer tomograph RayScan 250E. (a,d) Negative control (purple) and Geistlich Bio-Oss ${ }^{\circledR}$ (blue). (b,e) Pure PLA (blue) and PLA/HA (purple) scaffolds. (c,f) PLA/HA cellularised with dental pulp stem cells (blue) and PLA/HA ECM scaffolds (purple).
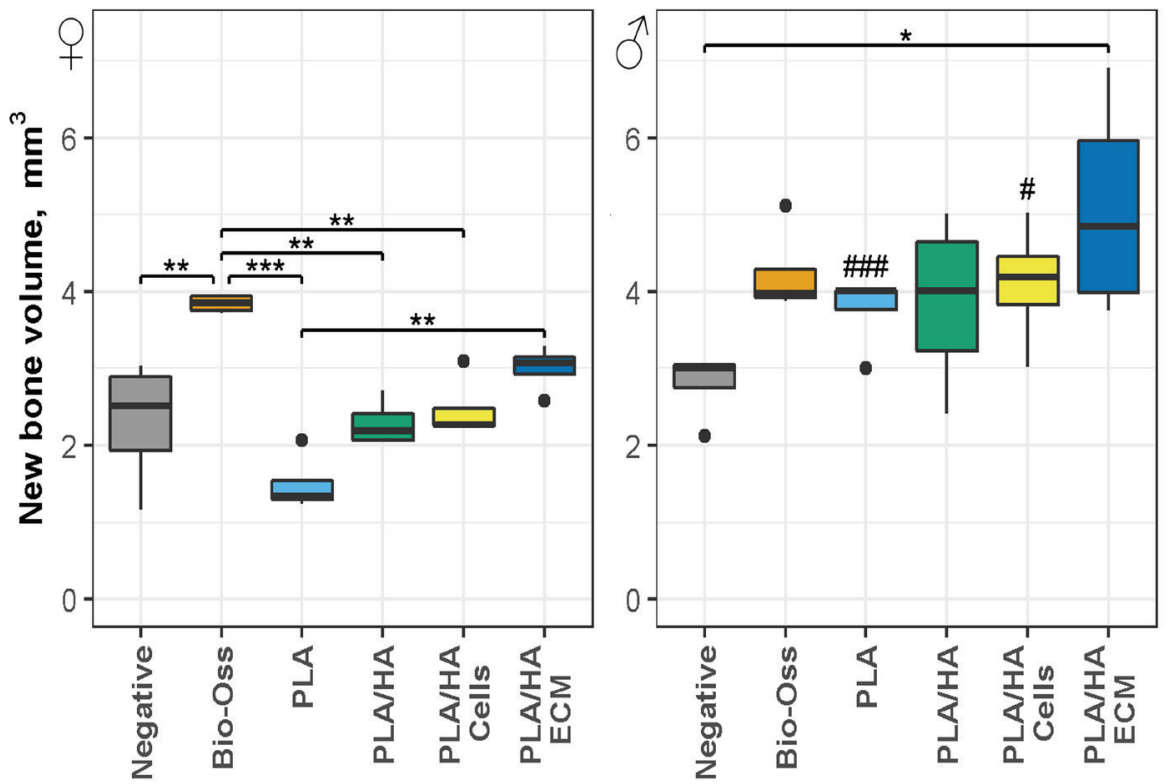

Fig. 5. $\mu \mathrm{CT}$ results. Box plots representing newly formed bone volume $\left(\mathrm{BV}, \mathrm{mm}^{3}\right)$, according to sample groups and gender. ${ }^{*}{ }^{* *}$ and ${ }^{* * *}$ mark the statistically significant differences between the groups at $p<0.05, p<0.01$ and $p<0.001$, respectively. \#, \#\# and \#\#\# mark the statistically significant differences between the gender in the same sample group at $p<0.05, p<0.01$ and $p<0.001$, respectively. 
A statistically significant difference was found between the Bio-Oss group and negative control in female rats, PLA/HA ECM group and negative control in male rats (Fig. 5). Moreover, $\mu \mathrm{CT}$ evaluation showed a statistically significant difference between the Bio-Oss and PLA groups, Bio-Oss and PLA/HA, Bio-Oss and cellularised PLA/HA groups, PLA and PLA/HA ECM groups in female rats (Fig. 5).

\section{Qualitative histology}

The histological slides for all groups after 8 weeks of healing are shown in Fig. 6. Histologically, the analysed biopsy contained connective tissue, residual grafting material, and newly-formed bone. The formation of up to $0.3 \mathrm{~mm}$ thin connective tissue was observed in the negative control group (Fig. 6a). The thickness of the connective tissue varied from $1.0 \mathrm{~mm}$ to $2.0 \mathrm{~mm}$ in the other sample groups (Fig. $6 \mathbf{b}-\mathbf{f})$. Lymphocytes were found mostly in the PLA group (Fig. 6c).

More new bone was forming towards the centre of the defect in the negative control group compared to PLA or PLA/HA groups. However, the layer of the new bone was thinner, varying in thickness from
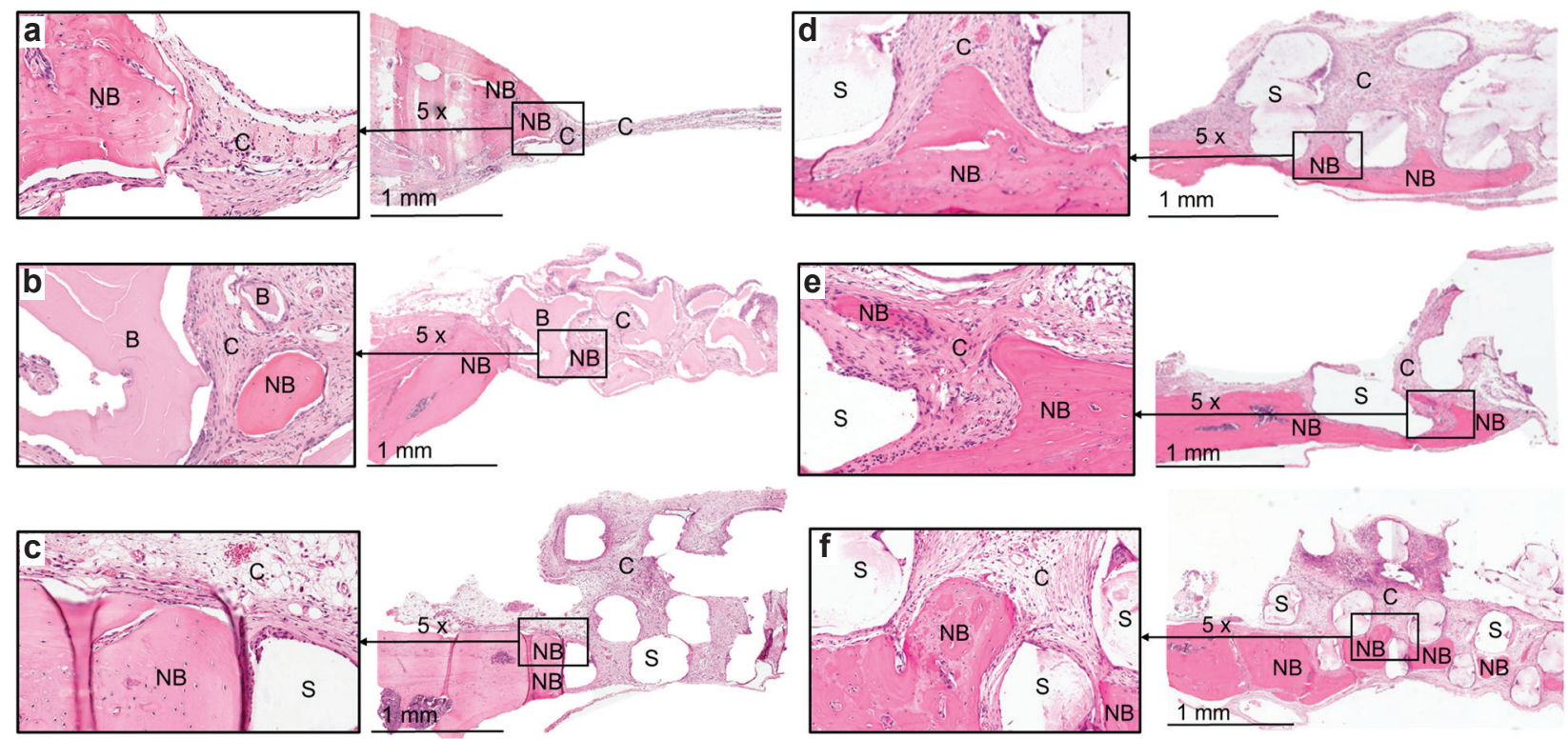

Fig. 6. Histological sections of the calvarial bone after 8 weeks of healing (haematoxylin and eosin staining). The sections were taken at the centre of the defect $(5.5 \mathrm{~mm})$. The left sides of the sections are shown for the typical findings of the samples for both genders. $\mathrm{NB}=$ newly formed bone, $\mathrm{B}=\mathrm{Bio}-\mathrm{Oss}, \mathrm{C}=$ connective tissue, $\mathrm{S}=$ scaffold (original magnification 2×). (a) Negative control; (b) Bio-Oss particles; (c) PLA group; (d) PLA/ HA group; (e) PLA/HA cellularised scaffolds with dental pulp stem cells; (f) PLA/HA ECM scaffolds.
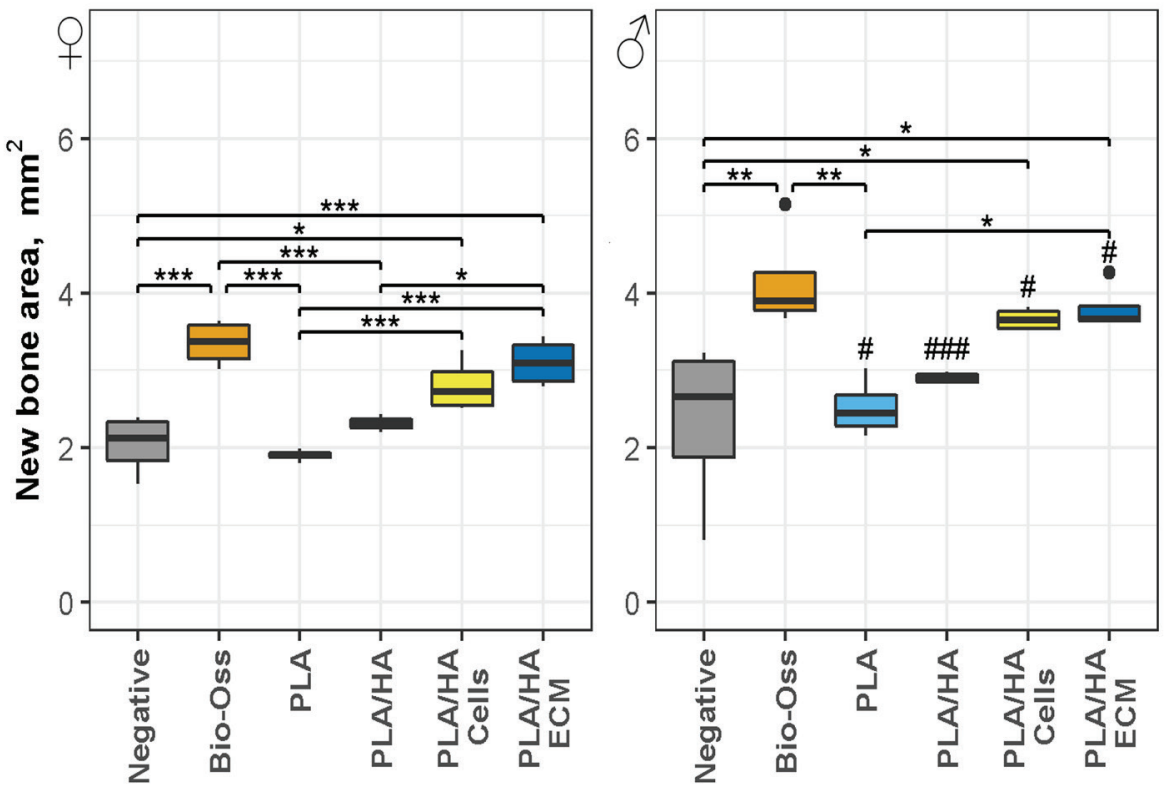

Fig. 7. Histology results of the area $\left(\mathrm{mm}^{2}\right)$ of newly formed bone according to sample groups and gender. ${ }^{*},{ }^{* *}$ and ${ }^{* * *}$ mark the statistically significant differences between the groups at $p<0.05, p<0.01$ and $p<0.001$, respectively. \#, \#\# and \#\# mark the statistically significant differences between the gender in the same sample group at $p<0.05, p<0.01$ and $p<0.001$, respectively. 
0.1 to $0.3 \mathrm{~mm}$. None of these defects were wholly healed after 8 weeks (Fig. 6a). In the other groups, the new bone formed a thicker layer, ranging from $0.3 \mathrm{~mm}$ to $1.0 \mathrm{~mm}$, but it was less developed towards the centre of the created defects (Fig. 6b-f). Some sections of PLA/HA, PLA/HA cellularised scaffolds with DPSC, and PLA/HA ECM scaffolds showed bridged new bone formation from one side to another with ingrowth between the scaffold layers (Fig. 6d-f). Furthermore, the new bone islands were found in the centre of defects of the Bio-Oss and PLA/HA ECM scaffolds (Fig. 6b,f). These new bone islands formed separately from the newly formed bone at the defect edges.

\section{Quantitative histology}

Histological evaluation showed no significant gender-specific differences in new bone formation of negative control and Bio-Oss groups $(p>0.05)$ (Fig. 7 , Table 1). However, gender-specific differences were found in all experimental groups (Fig. 7). Histological evaluation showed a statistically significant difference between negative control and Bio-Oss groups, negative control and PLA/HA cellularised scaffolds, negative control and PLA/HA ECM scaffolds, Bio-Oss and PLA groups, PLA and PLA/HA ECM groups in both gender rats (Fig. 7). Furthermore, a statistically significant difference was found between Bio-Oss and PLA/HA groups, PLA and cellularised PLA/HA groups, cellularised PLA/ HA and PLA/HA ECM groups in female rats (Fig. 7).

\section{Discussion}

The restoration of bone defects remains one of the most challenging problems in oral surgery. However, bone tissue engineering is a new promising treatment strategy (Pati et al., 2015). Currently, the calvarialrodent models have been extensively used and have contributed greatly to studying the processes of bone healing and regeneration (Gomes and Fernandes, 2011). However, controversial data of critical size defects in rats exist considering $8.0 \mathrm{~mm}$ or $5.0 \mathrm{~mm}$ to be of critical size (Gomes and Fernandes, 2011; Vajgel et al., 2014). Circular $5.5 \mathrm{~mm}$ calvarial defects were made in the current study, trying to keep them as large as possible, but still to be able to establish 2 defects per animal and to remain more consistent with the 3Rs concept by reducing the number of animals used. None of the created defects throughout the study healed spontaneously, so the term "criticalsize defect" can be used (Cooper et al., 2010). The euthanasia term varies among studies (McGovern et al., 2018). However, 8 weeks are usually chosen for the investigation of new bone formation in the rat model (DeNicolo et al., 2015). If the defects had been left for a longer healing time, it would have been possible that bigger differences could have occurred between the PLA and PLA/HA groups, due to PLA biodegradation products (Frohbergh et al., 2012).
The calvarial bone defect model in rodents is prevalent in similar studies. It is easy to do the surgery, as there is no need for external fixation of the biomaterials, and to evaluate the healing process using $\mu \mathrm{CT}$ and histology (Gomes and Fernandes, 2011). Moreover, such a study design allows researchers to test the bioactivity of different materials (granular, bulk or scaffold) and compare the results with existing data (Gomes and Fernandes, 2011). On the other hand, it is impossible to test the performance of the biomaterial under physiological mechanical loads (McGovern et al., 2018). The mandibular defect model shows the potential to be used as a critical size defect to evaluate preclinical therapies of bone regeneration. Important disadvantages of this defect model include poor visibility, difficult handling during surgical procedures, or damage to important adjacent anatomical structures (nasal bones, sinus, veins, and arteries), pain and inability to feed after the surgery could also be significant (Trejo-Iriartea et al., 2019).

It is known that female rats have lower regenerative capacity compared to males, due to lower mesenchymal stem cell numbers found in their bone marrow (Strube et al., 2009). This was the reason why PLA/HA scaffolds cellularised with DPSC were included in the study, hoping to improve the healing process. However, this hypothesis could not be confirmed as gender-specific differences were identified in new bone formation of cellularised PLA/HA scaffolds. Another possible gender-specific related reason for lower bone regeneration properties may be differences in sex steroids or growth hormone levels found in animal and human studies (Yao et al., 2013). Further research is needed to analyse these effects in bone regeneration. Moreover, universal scaffold composition was not found. In order to get the same comparable bone healing results in both genders, the osteoconductivity of the created scaffolds need to be improved. Histologically, all experimental sample groups had gender-specific differences. However, this information could have been missed if only males had been included in the research. Therefore, it is essential to have an equal number of males and females per study group. Unfortunately, only $1 \%$ of surgical research papers on rodents analysed results by sex (Beery, 2018).

Scaffold architecture is of critical importance for bone regeneration. Optimal pore size, ranging from 200 to $500 \mu \mathrm{m}$, is considered ideal for bone regeneration and vascularisation (Son et al., 2013). Typically, it is known that the size of the macro-pores of the scaffold cannot be smaller than $350 \mu \mathrm{m}$ because of the cell migration to the site of the defect and bone production. The size of micropores, important for liquid diffusion, has to be less than $10 \mu \mathrm{m}$ (Shamsoddin et al., 2019; Šponer et al., 2014). The scaffold threads should form hexagonal or octagonal shapes or be composed with an angle of $60^{\circ}$ to each other (Maisani et al., 2017). Such an internal structure is adapted to osteoblast migration and growth (Han et al., 2018; Wu et al., 2015). The 
thickness of the average rat calvarial bones was about $1 \mathrm{~mm}$, so the scaffolds were implanted into the defects with the "over-inlay" surgical technique. Therefore, the 3D structure could have been created to ensure the requirements of the bone scaffold architecture.

Bio-Oss is one of the most often used inorganic bovine bone xenografts in regenerative bone procedures (Shamsoddin et al., 2019) due to its adequate new bone formation, low reabsorption rate, osteoconductive characteristics, and compensation for the natural bone resorption caused by remodelling. It showed no significant gender-specific differences in new bone formation in the current study. BioOss and PLA/HA ECM groups, especially in male rats, showed the best osteoregenerative potential and confirmed the working hypothesis. Also, the new bone islands were found in the centre of the defect only in these 2 groups. However, there was no statistically significant difference between BioOss and PLA/HA groups in male rats. One study, which compared Bio-Oss and PLGA/HA scaffolds in the same experimental model also confirmed that bone-forming ability was comparable between these 2 materials, yet there only male rats were used (Kim and Kim, 2008).

ECM-coated scaffolds have received increased interest for bone tissue regeneration due to retained native biological molecules, which enhance cellular adhesion, proliferation, migration, and differentiation, but have a reduced effect on inflammation (Wu et al., 2019). The decellularisation procedure used in the current study was sufficient, and an evenly dispersed ECM network remained on the PLA/HA ECM scaffolds. PLA/HA ECM group showed better bone regeneration results when compared to cellularised PLA/HA scaffolds. Possible reasons for the differences in the cellularised scaffolds' osteoconductivity could be due to the onset of DPSC death at the centre of the scaffolds, due to malnutrition (Šponer et al., 2014), mechanical injury during operation procedure (Rai et al., 2005), bleeding, or insufficient blood circulation in bone defects (Kang et al., 2019). The cellular materials (DNA, signalling molecules, etc.) are released into the extracellular fluid, promote inflammatory response (Rai et al., 2005), cause side effects, or even migrate to other organs of the body (Šponer et al., 2014). Moreover, even if the stem cells survive transplantation, their viability may be decreased significantly (Kang et al., 2019). Furthermore, neither of the tests revealed a statistically significant difference between the results of cellularised PLA/HA scaffolds and PLA/HA scaffolds. Further research is needed to characterise the role and the fate of grafted cells and how they interplay with resident cells at the edges of the bone defects (Maisani et al., 2017). Also, researchers need to assess whether the improved results of bone regeneration are worth the increased cost of the procedure.

In the current study, pure PLA scaffolds showed the least effect on new bone formation in the created defects. This could be due to the pronounced inflammation reaction, which was seen in the histology and confirmed by other authors (Maisani et al., 2017). PLA biodegradation products could also be acidifying the microenvironment and causing additional stress to the healing tissue. HA, which was included in the composite scaffold, has a positive effect on prolonging PLA degradation, thus reducing the acidity of the biodegrading scaffold and increasing osteoconductivity of the created scaffolds (Frohbergh et al., 2012). It is known that PLA/HA scaffolds with a ratio of $9: 1$ have positive effects in new bone formation in vitro and in vivo (Tayton et al., 2014). However, an increase in HA concentration can be expected to provide better osteoinductive potential and be associated with higher levels of new bone formation (Han et al., 2018). Moreover, improved biodegradability, increased ability to absorb the water and improved tensile strength was noticed when the amount of HA was increased from 10 to $50 \%$ in the composite mixture (Linh et al., 2013). Further research is focused on the creation of a 3D composite PLA/HA scaffold with a higher amount of HA.

\section{Conclusion}

The bone-forming ability was comparable between the Bio-Oss and PLA/HA ECM scaffolds, especially in male rats. PLA/HA scaffolds have the potential of being used in bone tissue engineering, especially combined with the ECM. Further research is needed to analyse the effect of ECM and different PLA/HA ratio for osteoregeneration.

\section{Acknowledgments and disclosure statements}

The authors report no conflicts of interest related to this study. The authors would like to thank Sima Rekstyte (Laser Research Centre, Lithuania) and Sarunas Paulauskas (3d Creative, Lithuania) for printing the scaffolds. This research was supported by the Research Council of Lithuania, Grant No. MIP-15552.

\section{References}

Addi C, Murschel F, De Crescenzo G (2017) Design and use of chimeric proteins containing a collagen-binding domain for wound healing and bone regeneration. Tissue Eng Part B Rev 23: 163-182.

Alksne M, Simoliunas E, Kalvaityte M, Skliutas E, Rinkunaite I, Gendviliene I, Baltriukiene D, Rutkunas V, Bukelskiene V (2019) The effect of larger than cell diameter polylactic acid surface patterns on osteogenic differentiation of rat dental pulp stem cells. J Biomed Mater Res A 107: 174-186.

Alksne M, Kalvaityte M, Simoliunas E, Rinkunaite I, Gendviliene I, Locs J, Rutkunas V, Bukelskiene V (2020) In vitro comparison of 3D printed polylactic 
acid/hydroxyapatite and polylactic acid/bioglass composite scaffolds: insights into materials for bone regeneration. J Mech Behav Biomed Mater 104: 103641. DOI: 10.1016/j.jmbbm.2020.103641.

Alom N, Amer M, Marrelli M, Paduano F, Shakesheff KM, White LJ (2017) Decellularized bone extracellular matrix and human dental pulp stem cells as a construct for bone regeneration. J Biomater Sci Polym Ed 28: 730-748.

Anagnostopoulos AK, Calciolari E, Dereka X, Donos N, Mardas N, Tsangaris GT (2018) Protein expression during early stages of bone regeneration under hydrophobic and hydrophilic titanium domes. A pilot study. J Periodontal Res. 53: 174-187.

Antebi B, Zhang Z, Wang Y, Lu Z, Chen XD, Ling J (2015) Stromal-cell-derived extracellular matrix promotes the proliferation and retains the osteogenic differentiation capacity of mesenchymal stem cells on three-dimensional scaffolds. Tissue Eng Part C Methods 21: 171-181.

Ballini A, Cantore S, Scacco S, Coletti D, Tatullo M (2018) Mesenchymal stem cells as promoters, enhancers, and playmakers of the translational regenerative medicine 2018. Stem Cells Int 2018: 6927401. DOI: $10.1155 / 2018 / 6927401$.

Beery AK (2018). Inclusion of females does not increase variability in rodent research studies. Curr Opin Behav Sci 23: 143-149.

Bhatt RA, Rozental TD (2012) Bone graft substitutes. Hand Clin 28: 457-468.

Bonnans C, Chou J, Werb Z (2014) Remodelling the extracellular matrix in development and disease. Nat Rev Mol Cell Biol 15: 786-801.

Campana V, Milano G, Pagano E, Barba M, Cicione C, Salonna G, Lattanzi W, Logroscino G (2014) Bone substitutes in orthopaedic surgery: from basic science to clinical practice. J Mater Sci Mater Med 25: 24452461.

Cha HS, Kim JW, Hwang JH, Ahn KM (2016) Frequency of bone graft in implant surgery. Maxillofac Plast Reconstr Surg 38: 19. DOI: 10.1186/ s40902-016-0064-2.

Cooper GM, Mooney MP, Gosain AK, Campbell PG, Losee JE, Huard J (2010) Testing the critical size in calvarial bone defects: revisiting the concept of a critical-size defect. Plast Reconstr Surg 125: 1685-1692.

Costantino PD, Hiltzik DH, Sen C, Friedman CD, Kveton JF, Snyderman CF, Gnoy AR (2001) Sphenoethmoid cerebrospinal fluid leak repair with hydroxyapatite cement. Arch Otolaryngol Head Neck Surg 127: 588-593.

DeNicolo PJ, Guyton MK, Cuenin MF, Hokett SD, Sharawy M, Borke J, McPherson $3^{\text {rd }}$ JC (2015) Histologic evaluation of osseous regeneration following combination therapy with platelet-rich plasma and Bio-oss in a rat calvarial critical-size defect model. J Oral Implantol 41: 543-549.

Fricain JC, Schlaubitz S, Le Visage C, Arnault I, Derkaoui SM, Siadous R, Catros S, Lalande C, Bareille R, Renard M, Fabre T, Cornet S, Durand M, Léonard A, Sahraoui N, Letourneur D, Amédée
J (2013) A nano-hydroxyapatite - pullulan/dextran polysaccharide composite macroporous material for bone tissue engineering. Biomaterials 34: 2947-2959.

Frohbergh ME, Katsman A, Botta GP, Lazarovici P, Schauer CL, Wegst UGK, lelkes PI (2012) Electrospun hydroxyapatite-containing chitosan nanofibers crosslinked with genipin for bone tissue engineering. Biomaterials 33: 9167-9178.

Gendviliene I, Simoliunas E, Rekstyte S, Malinauskas M, Zaleckas L, Jegelevicius D, Bukelskiene V, Rutkunas V (2020) Assessment of the morphology and dimensional accuracy of 3D printed PLA and PLA/HAp scaffolds. J Mech Behav Biomed Mater 104: 103616. DOI: 10.1016/j.jmbbm.2020.103616

Gomes PS, Fernandes MH (2011) Rodent models in bone-related research: the relevance of calvarial defects in the assessment of bone regeneration strategies. Lab Anim 45: 14-24.

Graziano A, Aquino R, Laino G, Papaccio G. (2008) Dental pulp stem cells: a promising tool for bone regeneration. Stem Cell Rev 4: 21-26.

Han J, Baojin M, Hongrui L, Ting W, Fang W, Chengjia X, Minqi L, Hong L, Shaohua G (2018) Hydroxyapatite nanowires modified polylactic acid membrane plays barrier/osteoinduction dual roles and promotes bone regeneration in a rat mandible defect model. J Biomed Mater Res A 106: 3099-3110.

Hopcraft MS, Morgan MV, Satur JG, Wright FA (2012) Edentulism and dental caries in Victorian nursing homes. Gerodontology 29: e512-e519.

Jordana F, Visage C, Weiss P (2017) Substituts osseux. Med Sci (Paris) 33: 60-65.

Jung RE, Fenner N, Hämmerle CHF, Zitzmann NU (2013) Long-term outcome of implants placed with guided bone regeneration (GBR) using resorbable and non-resorbable membranes after 12-14 years. Clin Oral Implants Res 24: 1065-1073.

Kang SH, Park JB, Kim I, Lee W, Kim H (2019). Assessment of stem cell viability in the initial healing period in rabbits with a cranial bone defect according to the type and form of scaffold. J Periodontal Implant Sci 49: 258-267.

Kim SS, Kim BS (2008) Comparison of osteogenic potential between apatite-coated poly(lactide-coglycolide) / hydroxyapatite particulates and Bio-Oss. Dent Mater J 27: 368-375.

Langhans MT, Yu S, Tuan RS (2016) Stem cells in skeletal tissue engineering: technologies and models. Curr Stem Cell Res Ther 11: 453-474.

Leventis M, Fairbairn P, Mangham C, Galanos A, Vasiliadis O, Papavasileiou D, Horowitz R (2018) Bone healing in rabbit calvaria defects using a synthetic bone substitute: a histological and micro-CT comparative study. Materials 11: 2004. DOI: 10.3390/ ma11102004.

Li X, Chu CL, Liu L, Liu XL, Bai J, Guo C, Xue F, Lin PH, Chu PK (2015) Biodegradable polylactic acid based-composite reinforced unidirectionally with high-strength magnesium alloy wires. Biomaterials 49: 135-144. 
Liang C, Lin X, Wang S-L, Guo L-H, Wang X-Y, Li J (2017) Osteogenic potential of three different autogenous bone particles harvested during implant surgery. Oral Dis 23: 1099-1108.

Linh NTB, Min YK, Lee BT (2013) Hybrid hydroxyapatite nanoparticles-loaded PCL/GE blend fibers for bone tissue engineering. J Biomater Sci Polym Ed 24: 520-538.

Maisani M, Pezzoli D, Chassande O, Mantovani D (2017) Cellularizing hydrogel-based scaffolds to repair bone tissue: how to create a physiologically relevant micro-environment? J Tissue Eng. 8: 2041731417712073 . DOI: 10.1177/2041731417712073.

McGovern JA, Griffin M, Hutmacher DW (2018) Animal models for bone tissue engineering and modelling disease. Dis Model Mech 11: dmm033084. DOI: $10.1242 / \mathrm{dmm} .033084$.

Nakajima K, Kunimatsu R, Ando K, Ando T, Hayashi Y, Kihara T, Hiraki T, Tsuka Y, Abe T, Kaku M, Nikawa H, Takata T, Tanne K, Tanimoto K (2016) Comparison of the bone regeneration ability between stem cells from human exfoliated deciduous teeth, human dental pulp stem cells and human bone marrow mesenchymal stem cells. Biochem Biophys Res Commun 497: 876-882.

Narayanan G, Vernekar VN, Kuyinu EL, Laurencin CT (2016) Poly (lactic acid)-based biomaterials for orthopaedic regenerative engineering. Adv Drug Deliv Rev 107: 247-276.

Neto AS, Ferreira JMF (2018) Synthetic and marine-derived porous scaffolds for bone tissue engineering. Materials (Basel) 11: 1702. DOI:10.3390/ ma11091702.

Pati F, Song T-H, Rijal G, Jang J, Kim SW, Cho D-W (2015) Ornamenting 3D printed scaffolds with celllaid extracellular matrix for bone tissue regeneration. Biomaterials 37: 230-241.

Rai NK, Tripathi K, Sharma D, Shukla VK (2005). Apoptosis: a basic physiologic process in wound healing. Int J Low Extrem Wounds 4: 138-144.

Saintrain MV, de Souza EH (2012) Impact of tooth loss on the quality of life. Gerodontology 29: e632-e636.

Shamsoddin E, Houshmand B, Golabgiran M (2019) Biomaterial selection for bone augmentation in implant dentistry: a systematic review. J Adv Pharm Technol Res 10: 46-50.

Sheikh Z, Najeeb S, Khurshid SZ, Verma V, Rashid H, Glogauer M (2015) Biodegradable materials for bone repair and tissue engineering applications. Materials (Basel) 8: 5744-5794.

Son SR, Linh NB, Yang HM, Lee BT (2013) In vitro and in vivo evaluation of electrospun PCL/ PMMA fibrous scaffolds for bone regeneration. Sci Technol Adv Mater 14: 015009. DOI: 10.1088/14686996/14/1/015009.
Strube P, Mehta M, Baerenwaldt A, Trippens J, Wilson CJ, Ode A, Perka C, Duda GN, Kasper G (2009) Sex-specific compromised bone healing in female rats might be associated with a decrease in mesenchymal stem cell quantity. Bone 45: 1065-1072.

Sveikata K, Balciuniene I, Tutkuviene J (2012) Needs for prosthetic treatment in Vilnius population at the age over 45 years old. Stomatologija. 14: 81-84.

Šponer P, Kučera T, Diaz-Garcia D, Filip S (2014) The role of mesenchymal stem cells in bone repair and regeneration. Eur J Orthop Surg Traumatol 24: 257-262.

Tayton E, Purcell M, Aarvold A, Smith JO, Briscoe A, Kanczler JM, Shakesheff KM, Howdle SM, Dunlop DG, Oreffo RO (2014) A comparison of polymer and polymer-hydroxyapatite composite tissue engineered scaffolds for use in bone regeneration. An in vitro and in vivo study. J Biomed Mater Res A 102: 2613-2624.

Tyler B, Gullotti D, Mangraviti A, Utsuki T, Brem H (2016) Polylactic acid (PLA) controlled delivery carriers for biomedical applications. Adv Drug Deliv Rev 107: 163-715.

Trejo-Iriartea CG, Serrano-Bellob J, GutiérrezEscalonaa R, Mercado-Marquesc C, GarcíaHonduvillade N, Buján-Varelad J, Medina LA (2019) Evaluation of bone regeneration in a critical size cortical bone defect in rat mandible using microCT and histological analysis. Arch Oral Biol 101: 165-171.

Vajgel A, Mardas N, Farias BC, Petrie A, Cimões R, Donos N (2014) A systematic review on the critical size defect model. Clin Oral Implants Res 25: 879-893.

Valenti MT, Carbonare LD, Mottes M (2016) Osteogenic differentiation in healthy and pathological conditions. Int J Mol Sci 18: 41. DOI: 10.3390/ ijms18010041.

Wu D, Chen X, Chen T, Ding C, Wu W, Li J (2015) Substrate-anchored and degradation-sensitive antiinflammatory coatings for implant materials. Sci Rep 5: 11105. DOI: 10.1038/srep11105.

Wu YA, Chiu YC, Lin YH, Ho CC, Shie MY, Chen YW (2019) 3D-printed bioactive calcium silicate/poly$\varepsilon$-caprolactone bioscaffolds modified with biomimetic extracellular matrices for bone regeneration. Int J Mol Sci 20: 942. DOI: 10.3390/ijms20040942.

Yao X, Carleton SM, Kettle AD, Melander J, Phillips CL, Wang Y (2013) Gender-dependence of bone structure and properties in adult osteogenesis imperfecta murine model. Ann Biomed Eng 41: 11391149.

Editor's note: There were no questions from reviewers for this paper, therefore there is no Discussion with Reviewers section. The Scientific Editor responsible for this paper was Chris Evans. 